\title{
Distance-Learning Initiatives Targeting Non-physician Anesthesia Providers in Low-Resource Environments
}

\author{
Shristi Shah ${ }^{1,2}$ (D) Oliver Ross ${ }^{2,3} \cdot$ Stephen Pickering ${ }^{2,4}$ \\ Accepted: 21 December 2020 / Published online: 26 January 2021 \\ (C) The Author(s), under exclusive licence to Springer Science+Business Media, LLC part of Springer Nature 2021
}

\begin{abstract}
Purpose of Review "Distance-learning" encompasses a variety of didactics, from self-directed online learning to focused courses and programs. Despite increasing internet availability, focused distance-learning courses are rarely practiced in low- or middleincome countries, particularly among non-physician anesthetists. This review aims to discuss the availability, significance, and challenges of distance-learning programs for non-physician anesthesia providers in low-resource settings.

Recent Findings Task shifting and sharing in anesthesia remains essential in low-resource settings to meet the demand of surgical need. Distance-learning may be the ideal option in these settings, as it can be used to train the individual at their workplace even in remote areas. Different models and techniques are described. Success depends on the course design, communication strategies, handling of technical issues, and support mechanisms.

Summary Distance-learning should be an essential part of training and in-service support for non-physician anesthetists. Global advocates of safe, effective anesthesia services need to support the development and delivery of distance-learning courses.
\end{abstract}

Keywords Distance-learning $\cdot$ Blended learning $\cdot$ Non-physician anesthetists $\cdot$ Low-resource setting $\cdot$ Low- and middle-income country

\section{Introduction}

There are an estimated 5 billion people in the world, mainly in low- and middle- income countries (LMICs), who struggle to access safe, affordable, and timely surgical and anesthetic care [1]. Surgical care was not a public health priority until 2015

This article is part of the Topical Collection on Global Health Anesthesia

Shristi Shah

shristi97@gmail.com

Oliver Ross

oliver.ross1@btinternet.com

Stephen Pickering

pickinnepal@gmail.com

1 National Academy of Medical Sciences, Mahaboudha, Nepal

2 Nick Simons Institute, GPO 8975; EPC 1813, Sanepa, Lalitpur, Nepal

3 University Hospital Southampton NHS foundation Trust, Tremona Road, Southampton SO16 6YD, UK

4 Calvary Mater Newcastle, Edith and Platt St, Waratah, NSW 2298, Australia when the World Health Assembly recognized it as an essential component of universal health coverage [2]. Now that surgery is recognized as a part of universal health coverage, the lack of resources to deliver safe surgical care needs to be addressed. There remains an insufficient number of trained physicians available to provide anesthesia in LMICs [3, 4]. Task shifting to non-physician anesthesia providers is well established, remains necessary, and is widespread. High-quality training and continued professional development is an essential part of scaling up safe surgery and anesthesia. The WHO recommends targeted accessible continuing education as a key to support rural health worker retention. In many LMIC, when an anesthesia provider leaves their place of work to engage in further training or professional development, the services they were providing cease. Distance-learning may facilitate further training for these healthcare workers without decreasing their clinical service provision.

Distance-learning is gaining popularity in the education system worldwide, because it allows for a learner's "own pace and place." During the Covid-19 pandemic, the potential hazard of in-person training has given impetus to distancelearning initiatives. The pandemic has also driven delivery of medical education and continued professional development 
(CPD) online. Anesthesiology leaders worldwide have met this new challenge by developing online educational courses like e-SAFE [5*0] but there is much more to do to effectively reach anesthesia providers in low-resource settings. The purpose of this review is to evaluate the models for distancelearning for non-physician anesthetists in low-resource settings.

\section{Search Strategy/Method}

For this narrative review, articles were searched using Google scholar, Medline, Education Resources Information Center (ERIC), and Pub med. Articles initially were searched using keywords as distance-learning, non-doctor anesthesia provider, and low-resource setting. There was limited number of articles published in this field. Therefore, a broader range of search criteria was used with the main keywords as distancelearning and anesthesia.

\section{Distance-Learning: an Overview and Applications in Anesthesia}

Distance-learning is now part of the mainstream in higher education: there has been a 5\% annual increase in enrolment in distance education programs in the USA in recent years [6]. Contrary to higher education in high-income countries, most anesthesia training in LMICs is still based on classroom teaching and in-person supervision. Barriers to implementation of distance-learning in LMICs include limited access to internet services and limited courses tailored for LMIC providers.

Pecka et al. [7] describe key components to develop the best distance-learning model (Fig. 1): (1) social presence (ability of student to be part of an online community), (2) teaching presence (direction of the course given by teachers), and (3) cognitive presence (Intellectual environment reflecting collaborative learning process and including higher order thinking). This Community of Inquiry Model (COI) implies that a group

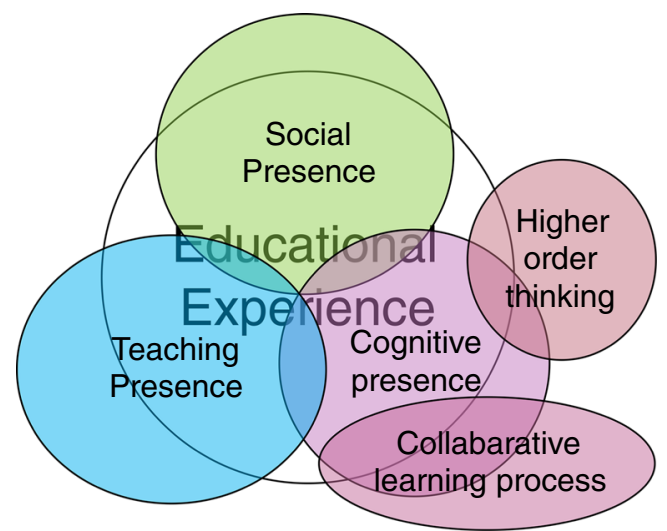

Fig. 1 Community of inquiry model (COI) for distance learning (ref 7) educational approach to distance-learning (collaborative learning process) improves the learning curve more than individual learning. Distance-learning can also be synchronous or asynchronous. Synchronous, or "real-time," learning allows for a group educational approach. Asynchronous learning, where the learner accesses material in their own time, offers flexibility but requires more motivation or discipline due to the lack of real time interaction with others. A survey among Canadian anesthesia residents found that $60 \%$ of respondents used asynchronous podcasts for learning [8•]. Survey respondents preferred podcasts that contained procedural skills, journal article summaries, and case presentations of 5 to $15 \mathrm{~min}$ in duration. Podcasts can be a cheap and effective learning tool for anesthesia providers in remote locations, if well-developed according to the need of the low-resource setting and vetted for clinical content.

Informal social networks like Facebook, Twitter, and YouTube also provide educational support for providers in remote settings. These include existing static teaching resources (e.g., documents, algorithms, illustrations, videos), animated videos and podcasts, and applications supporting augmented and/or virtual reality (e.g., virtual airway visualized on mobile phone). These free, open source materials may also include misleading or incorrect information. This reinforces the need for online educational materials to be properly vetted. These sites are still valuable and could be repurposed and formalized to create vetted networks. Edgcombe [9] emphasized the importance of mobile technology-based training tools for the enhancement of emergency care in LMICs and this may have applications in anesthesia as well. Vetted opensource materials are widespread and include the WFSA Virtual library [10], Tutorial of the week, Update in anesthesia and video library, e-Learning Anesthesia (eLA) and eSAFE, and essential anesthesia e-packages [5••]. These materials provide diverse educational content and are widely viewed. However, individuals using these resources do not receive guided synchronous distance-learning in a group environment, a designated educational program, or specific qualifications. Non-physician anesthesia providers may have received their initial training and written materials in their local language or specifically simplified English, whereas physician anesthesiologists are often taught entirely in English, and use English texts and journals in their education. Goodquality training materials may be of little use if there is a significant language barrier preventing clear understanding. Educational materials need to be more than vetted as up to date and accurate, but also comprehensible. The remote anesthesia teacher in a blended learning course may have to play an extra role in this sense.

Continuous innovation in treatment guidelines, new drugs, and new equipment in anesthesia all require ongoing education and professional development. This may be especially important for clinically and geographically isolated providers 
in LMIC or rural areas, where surgical complications are more frequent. In Sub-Saharan Africa, perioperative mortality is twice as high as the global average [11]. Most anesthesiarelated mortality could be mitigated by improved and consistent training. For example, a study in Malawi found that one of the crucial factors affecting maternal mortality after cesarean delivery was limitations in training [12]. Kiwanuka et al. [13••] studied the effectiveness of anesthesia education delivered by synchronous videoconferencing between the Massachusetts General Hospital, Boston, USA, and Mbarara Regional Referral Hospital, Uganda. They delivered 31 small group lectures and 4 alternative teaching formats (e.g., Grand Rounds or multidisciplinary presentations) via Skype over 1 year. All residents who attended the lectures, either in-person or via videoconferencing, completed pre- and post-lecture tests. There was significant improvement in post-test scores in both groups. This study shows that knowledge transmission is possible with synchronous videoconferencing. It also demonstrated the use of free Skype videoconferencing software. Multiple international anesthesia societies have worked in Uganda to improve anesthesia training, including e-learning and hands on training by visiting faculties. This approach has resulted in increased numbers of anesthesia providers in the country as well as new investments in non-physician anesthesia provider training courses [14].

\section{Blended Distance-Learning: a Case Study From Nepal}

"Blended" learning describes the combination of online digital learning with traditional in-person learning. For example, distance-learning for the registered nurse first assistant program at Rock Valley College in the USA successfully covered $70 \%$ of teaching by distance-learning and the remaining teaching as in-person training workshops [15]. This model can be practiced in low-resource settings with modification. Our group in Nepal created a blended learning program for nonphysician anesthetists to improve their skills and knowledge [16••]. The curriculum was developed by international and domestic anesthesiologists by adapting content from internationally published textbooks and courses. Twenty-two nonphysician anesthesia providers working in remote areas were given a tablet pre-loaded with training materials and internet accessibility. Each participant was assigned a physician mentor to liaise with by phone or internet. The de novo course was designed to be completed over 1 year with 3 weeks of traditional in-person teaching, and all the remaining time as distance-learning. In-person learning was utilized mainly to teach essential anesthesia skills along with critical thinking. The course was linked to clinical case logbook completion, educational supervision, and culminated in an exam for qualification from Nepal's National Health Training Council. This course was funded by a rural health NGO working in Nepal.

Electronic logbook recording is one of the more innovative parts of our blended distance-learning course [17]. All participants must record the cases they have completed successfully, as well as any complications. This is intended to generate self-reflection, stimulate discussion, and generate learning points to better handle critical situations; this contributes to the cognitive presence or intellectual environment as described by Pecka et al. Limitations of the blended distancelearning course include start-up costs, need for technical staff support, and the need for ongoing course development. A blended distance-learning course in its initial phase may be more expensive than traditional in-person training [18], but it should be noted that most start-up costs are fixed investment costs rather than recurring costs. Another obstacle is internet connectivity and quality in the LMICs. This problem can be minimized by offering a downloadable version of the course, limiting the necessary on-line time.

\section{Challenges of Distance-Learning}

Multiple factors have been found to affect attrition in distancelearning [19]. Time and motivation to complete educational or professional development activities should not be assumed. Challenging work environments with limited support, complex cases, and additional clinical responsibilities on the ward or elsewhere are all challenges for non-physician anesthesia providers in LMICs [20]. Course developers should keep these challenging circumstances in mind and consider active involvement of stakeholders in course development as well as adoption of easy to use accessible virtual learning platforms. Support for affordable high-quality internet and course time flexibility can also help to further mitigate some of the challenges [21, 22].

In Nepal, it is a standard practice to give daily financial allowance to government workers for attending a course, whether on-site and away from base hospital. Likewise, performance-based financial incentives are used to enhance motivation and healthcare delivery by rural health-workers in general [23]. However, as these are not yet widely practiced for distance learning, provision of allowance may increase course recruitment and decrease program attrition rates.

\section{An Ideal Distance-Learning Package: Recommendations}

- De novo curriculum and content to be consistent with international standards for anesthesia but locally adapted and relevant to target participants. 
- Affordable or ideally open access

- Any open-source material should be filtered or vetted and its use guided by teachers.

- Courses should ideally build towards exams or accreditation of qualification

- Clinical caseload or educational progress logbooks to improve motivation and monitoring

- Consider blended learning: add in-person educational and clinical exposure whenever possible

- Regular educational coaching and mitigation of low motivation to avoid dropouts.

\section{Conclusion}

Task shifting in anesthesia is widespread and remains necessary. However, it comes with a responsibility to train and support these non-physician anesthetists to maximize anesthesia safety and efficacy. In this era of global connectivity and pandemic, anesthesiolgy should utilize distance-learning for all trainees and especially for non-physician anesthesia providers in low-resourced areas or LMICs. Distance-learning or blended distance-learning can be cost-effective. Global advocates of safe anesthesia need to support the development and delivery of distance-learning courses for anesthesia providers in low-resource settings.

\section{Compliance with Ethical Standards}

Conflict of Interest There are no conflicts of interest.

Human and Animal Rights This article does not contain any studies with human or animal subjects performed by any of the authors.

\section{References}

Papers of particular interest, published recently, have been highlighted as:

- Of importance

•- Of major importance

1. Meara JG, Leather AJM, Hagander L, et al. Global surgery 2030: evidence and solutions for achieving health, welfare, and economic development. Lancet. 2015;386(9993):569-624.

2. WHO global initiative for emergency and essential surgical care. Sixth biennial and tenth anniversary meeting. 14-15 Dec 2015. WHO Headquarter, Geneva, Switzerland. Available at: WHO/ HIS/SDS/2016.11

3. Kempthorne P, Morriss W, Mellin-Olsen J, Gore-Booth J. The WFSA global anesthesia workforce survey. Anesth Analg. 2017;125(3):981-990(10). https://doi.org/10.1213/ANE. 0000000000002258 .
4. Dubowitz G, Detlefs S, Mc Queen KA. Global anesthesia workforce crisis: a preliminary survey revealing shortage contributing to undesirable outcomes and unsafe practices. World J Surg. 2010;34: 438-44. https://doi.org/10.1007/s00268-009-0229-6.

5.• e-SAFE. Royal College of Anaesthetists (RCoA) and Association of Anaesthetists of Great Britain and Ireland (AAGBI); second edition 2017. Available from: http://www.e-safe-anaesthesia.org. Accessed 4 Nov 2020. Online material available to everyone.

6. Jeong JS, Gonzalez-Gomez D, Canada-Canada F, et al. Effect of active learning methodologies on the students' emotions, selfefficacy beliefs and learning outcomes in a science distancelearning course. J Sci Educ Technol. 2019;9(2):217-27. https:// doi.org/10.3926/jotse.530.

7. Pecka SL, Kotcherlakota S, Berger AM. Community of inquiry model: advancing distance-learning in nurse anesthesia education. AANA. 2014;82(3):212-8.

8. Matava CT, Rosen D, Siu E, et al. eLearning among Canadian anesthesia residents: a survey of podcast use and content needs. BMC Med Educ. 2013;13:59. https://doi.org/10.1186/1472-692013-59 Considering the use of podcast in anesthesia which can be developed for the use by LMIC.

9. Edgcombe H, Paton C, English M. Enhancing emergency care in low-income countries using mobile technology-based training tools. Arch Dis Child. 2016;101:1149-52. https://doi.org/10.1136/ archdischild-2016-310875.

10. Virtual Library. World Federation of Societies of Anaesthesiologists. Available from: https://www.wfsahq.org/ virtual-library. Accessed 4 Nov 2020.

11. Biccard BM, Madiba TE, Kluyts HL, et al. Perioperative patient outcomes in the African surgical outcomes study: a 7-day prospective observational cohort study. Lancet. 2018;391(10130):158998. https://doi.org/10.1016/S0140-6736(18)30001-1.

12. Fenton P, Whitty CJM, Reynolds F. Caesarean section in Malawi: prospective study of early maternal and perinatal mortality. BMJ. 2003;327:587-92.

13.• Kiwanuka JK, Ttendo SS, Eromo E, et al. Synchronous distance anesthesia education by internet videoconference between Uganda and the United States. J Clin Anesth. 2015;27(6):499-503. https:// doi.org/10.1016/j.jclinane.2015.04.004 Well-studied course proving that knowledge transfer can be done in easier and cheaper way via videoconferencing.

14. Walker IA, Bashford T, Fitzgerald JE, Wilson IH. Improving anesthesia safety in low income regions of the world. Curr Anesthesiol Rep. 2014;4:90-9. https://doi.org/10.1007/s40140-014-0056-7.

15. Degon R. Distance-learning for the $\mathrm{RN}$ first assistant. AORN. 2010;91(1):146-53. https://doi.org/10.1016/j.aorn.2009.09.022.

16.• Shah S, Knoble S, Ross O, Pickering S. A blended learning program to upgrade the clinical competence of district non-doctor anesthesia providers in Nepal. World J Surg. 2017;41:3006-11. https://doi.org/10.1007/s00268-017-4273-3 Well-defined blended learning course designed for non-physician anesthetist of LMIC.

17. Shah S, Ross O, Pickering S, Knoble S, Rai I. Tablet e-Logbooks: four thousand clinical cases and complications e-logged by 14 nondoctor anesthesia providers in Nepal. Anesth Analg. 2017;125(4): 1337-41. https://doi.org/10.1213/ANE.0000000000002094.

18. Westover JH, Westover JP. Teaching hybrid courses across disciplines: effectively combining traditional learning and e-learning pedagogies. Int J Inf Educ Technol. 2014;4(1):93-6. https://doi. org/10.7763/IJIET.2014.V4.376.

19. Lee Y, Choi J, Kim T. Discriminating factors between completers of and dropouts from online learning courses. Br J Educ Technol. 2013;44(2):328-37. https://doi.org/10.1111/j.1467-8535.2012. 01306.x.

20. Ross O, Dali L, Rai S, et al. Anesthesia assistant follow- up enhancement program 2011-2012. Nepal. Nick Simons Institute 
2012. Available at: http://www.nsi.edu.np/research. Accessed 19 July 2020.

21. Moran AM, Coyle J, Pope R, et al. Supervision, support and mentoring interventions for health practitioners in rural and remote contexts: an integrative review and thematic synthesis of the literature to identify mechanisms for successful outcomes. Hum Resour Health. 2014;12:10. https://doi.org/10.1186/1478-4491-12-10.

22. Al-Balas M, Al-Balas HI, Jaber HM, et al. Distance learning in clinical medical education amid COVID-19 pandemic in Jordan: current situation, challenges, and perspectives. BMC Med Educ. 2020;20:341. https://doi.org/10.1186/s12909-020-02257-4.

23. Muthuri RNDK, Senkubuge F, Hongoro C. Determinants of motivation among healthcare workers in the East African community between 2009-2019: a systematic review. Healthcare (Basel). 2020;8(2):164. https://doi.org/10.3390/healthcare8020164.

Publisher's Note Springer Nature remains neutral with regard to jurisdictional claims in published maps and institutional affiliations. 